\title{
OCCURRENCE OF LOW BACK PAIN INEMPLOYEES OF THE NUTRITION AND CONSERVATION SECTORS OF A TERTIARY SERVICE IN THE CITY OF TEFÉ, AM
}

\author{
Wuerles Bessa Barbosa ${ }^{1, *}$ \\ 1.Secretaria Municipal de Saúde de Manaus, Manaus (AM), Brazil. \\ ${ }^{\star}$ Corresponding author: wuerlesbessa@gmail.com
}

\section{BACKGROUND}

The lumbar spine is responsible for supporting the head, trunk and upper limbs, and can be subjected to traction, compression and torsion forces. One of its main functions is to protect and provide protection to the central nervous system, in addition to providing remarkable mobility to the body. Therefore, common postures in the work environment, such as carrying weight and repetitive use of the same limb; increases the overload on the lumbar spine by its own gravitational force. The aim of this study was to evaluate the prevalence of low back pain in outsourced employees of the nutrition and conservation sectors of a tertiary service in Tefé, Amazonas state, Brazil, aiming to identify possible correlated factors, such as vicious postures, inadequate movements and ergonomically inappropriate materials.

\section{METHODS}

The study is cross-sectional, based on data collected through a questionnaire adapted from the Quebec back pain disability scale (QBPDS) in 2012. The population sample consisted of 48 employees aged between 20 and 65 years. A biomechanical analysis of the movements reported as the most uncomfortable during the workday was also carried out.

\section{RESULTS}

During the research, several biomechanically inadequate postures were verified by the participants of this study, such as keeping the load away from the vertical axis of the body, leaning forward during repetitive movements, performing continuous muscular effort and performing sudden and muscular movements, causing peaks of muscle tension. In addition, there were also short and frequent breaks during the workday ( $12 \mathrm{~h} / \mathrm{day}$ ), a fact that contributed to the onset of fatigue and muscle tension. Only 2 (4.2\%) employees did not report pain in the lower back, $72 \%$ had worked in the company for more than 3 years and $60 \%$ reported that when climbing and/or descending stairs with weight, the reported pain increased.

\section{CONCLUSION}

As the work was developed, it was possible to correlate the low back pain that occurs in nutrition and conservation workers on computed tomography with incorrect postures and movements. Thus, to reduce the frequency of arthralgias and myalgias, as well as tensions in the lumbar spine, it is essential that individuals who perform occupational activities in the places of this study are trained so that they know the ergonomically correct postures and that they can use ergonomically adapted equipment to every type of job and biotype.

\section{KEYWORDS}

Low back pain, Hospital, Tefé, Brazil. 